\title{
ANTONIO GARCÍA REINOSO: REFLEXIONES SOBRE UN DIBUJANTE ANDALUZ DEL SIGLO XVII
}

\section{ANTONIO GARCÍA REINOSO: REFLECTIONS ON A $17^{\mathrm{TH}}$ CENTURY ANDALUSIAN DRAFTSMAN}

\author{
Fuensanta García de la TORRE \\ Academia Andaluza de la Historia. España \\ ORCID: 0000-0002-3552-0941 \\ fuensanta.arteymuseo@gmail.com
}

\begin{abstract}
Antonio García Reinoso es un pintor barroco granadino que trabaja en diferentes lugares de Andalucía. A partir de 1672 se le sitúa en Córdoba, donde lleva a cabo parte de su producción artística. Pintor de mediana calidad y dibujante de una significativa capacidad, centra sus diseños en temas mitológicos y religiosos y trazas de retablos y elementos ornamentales y decorativos que demuestran su formación y singularidad, además de las influencias recibidas del entorno más próximo con Antonio del Castillo, Sebastián Martínez o Alonso Cano y de los grabados de Rubens.

Palabras clave: dibujo; barroco español; Andalucía; siglo XVII; Antonio García Reinoso.
\end{abstract}

Antonio García Reinoso is a Baroque painter from Granada who works in different parts of Andalusia. From 1672 he moves to Córdoba, where he carries out much of his artistic production. Medium quality painter and accomplished draftsman, he focuses his designs on mythological and religious themes and altarpieces as well as ornamental and decorative elements that demonstrate his training and singularity. In addition, he was influenced by his surrounding milieu -Antonio del Castillo, Sebastián Martínez and Alonso Cano- and the prints by Rubens.

Keywords: drawing; Spanish Baroque; Andalusia; $17^{\text {th }}$ century; Antonio García Reinoso.

Unas pocas líneas a pluma bien puestas, con un tinte de sombreado por arriba o por abajo, expresan los hechos mejor de cómo podrías conseguirlo de cualquier otro modo con el mismo gasto de tiempo.

John Ruskin, 1999: 104. 
Reflexionar sobre un artista aún pendiente de un estudio completo de su producción y de parte de su biografía, supone una aproximación al mismo sin llegar a conclusiones definitivas. Algunos de sus dibujos han sido publicados en catálogos de exposiciones de las colecciones del Museo de Bellas Artes de Córdoba, la Galleria degli Uffizi de Florencia, del Courtauld Institute de la Universidad de Londres o de la Biblioteca Nacional de España. También en publicaciones como El dibujo español de los siglos de oro (1980) y la Historia del dibujo en España. De la Edad Media a Goya (1986), de Alfonso E. Pérez Sánchez. A ello hay que agregar la memoria de licenciatura sobre el artista presentada por Pilar Manteca Cano en 1977. No obstante, en los últimos años se han dado a conocer bastantes datos, por lo que es necesario aún un profundo estudio general del maestro granadino. Revisando lo publicado, más lo que venimos investigando desde hace años y la diversidad de sus diseños, hacemos estas reflexiones que nos irán aproximando al análisis de su producción, distinguiendo la labor de un excelente dibujante y un mediocre pintor ${ }^{1}$.

El nacimiento de Antonio García Reinoso (Granada, 1623-Córdoba, 1677) fue situado por Palomino en Cabra (Córdoba), hasta que se documentó su origen granadino, aunque con siete años se sabe que residía con su familia en dicha población, donde aún permanece en 1646 cuando contrae matrimonio. De allí pasa a Jaén, donde debió ser discípulo de Sebastián Martínez (1615-1667), pintor jienense con claras influencias de Antonio del Castillo, Alonso Cano y la pintura de Corte. De Jaén se traslada a Granada para perfeccionar su estilo, hasta que en 1672 pasa a Córdoba según Palomino. El inicio del barroco cordobés parte de artistas manieristas y poco sabemos de cómo dibujaban Pablo de Céspedes, Juan de Peñalosa o Juan Luis Zambrano, a los que se atribuyen diseños en el Museo de Bellas Artes de Córdoba, en los Uffizi florentinos o en la antigua colección Boix, faltando por definir sus estilos y detallar atribuciones que perfilen su conocimiento y su influjo en maestros posteriores. Pero no se pueden analizar los dibujos de Reinoso sin conocer los de Antonio del Castillo (1616-1668), que ya fueron apreciados por Lázaro Díaz del Valle aún en vida del maestro. Con posterioridad, Palomino en 1724, Ceán Bermúdez en 1800, Priscilla Müller en 1963 y 2006, Pérez Sánchez en 1980 y 1986, Nancarrow en 1990, 1992, 1993, 1996, 2002 y 2004, Navarrete Prieto y García de la Torre, en 2008 y 2017 o Alonso del Moral, García de la Torre y Navarrete Prieto en 2016, relacionan más detalladamente las influencias de ambos maestros en Córdoba.

Poca información hay de su labor como pintor ya que, a pesar de estar documentada en varias ciudades, es escaso lo conservado o al menos lo correctamente identificado. Lo más conocido de su producción pictórica es una serie de cuatro

${ }^{1}$ Manteca Cano, 1977. Pérez Sánchez, 1980: 70-71; 1986: 309-312. García de la Torre, ver las referencias citadas en bibliografía, básicamente 1997; 2001; 2005; 2007; 2008, $2015 ; 2016$. 
lienzos de la Vida del rey San Fernando, de discreta calidad, comenzada en agosto de 1675 y finalizada un año después para la mezquita catedral de Córdoba ${ }^{2}$ y las pinturas murales de la capilla de Nuestro Padre Jesús Nazareno en las iglesias de Santa Marta de Martos (Jaén) y de San Miguel de Andújar (Jaén). A ello hay que añadir obras atribuidas en el Museo de Bellas Artes de Córdoba, en poblaciones de Córdoba, Jaén y Málaga, que corresponden a una polifacética producción en pintura mural y de caballete, dibujos religiosos, trazas y policromía de retablos, piezas de orfebrería o dorado y bruñido de elementos decorativos. Es curioso, frente a la mediana calidad de sus pinturas conocidas, que Palomino cite elogiosamente una pintura suya del Baño de Susana detallando que, "habiéndolo concluido y puesto en el patio a enjugar, un gorrioncillo viendo desde el tejado el país, las aguas y el estanque, bajó diferentes veces a ponerse en los remates del estanque, hallando siempre burlada su diligencia, con admiración de los circundantes, en crédito de la propiedad con que estaba ejecutado"3.

El análisis de García Reinoso dibujante debe hacerse en el contexto andaluz focalizado en Córdoba, Granada y Sevilla, centros destacados del dibujo barroco español junto a Madrid y Valencia. El dibujo barroco en Córdoba prácticamente se centra en Antonio del Castillo y Antonio García Reinoso, además de algún otro maestro de menor calidad y producción más limitada. En Granada, en la figura de Alonso Cano y de sus discípulos y, en Sevilla, en las creaciones de Herrera el Viejo, de su hijo Herrera el Mozo, de Juan de Valdés Leal o de Cornelio Schut. El diseño sevillano se vio reforzado tras la creación, a instancias de Murillo, de la academia fundada en 1660 en la Casa Lonja. Considerado tradicionalmente dicho maestro junto con Ribera y Cano, como los más insignes dibujantes españoles, no hay que olvidar en el entorno andaluz a los artistas mencionados, claves para un mejor conocimiento del diseño barroco español, bajo el flujo de influencias entre talleres y maestros con similares sistemas de trabajo y ciertas coincidencias tipológicas, técnicas y estéticas.

Frente al limitado valor de sus pinturas, sus dibujos descubren a un cualificado maestro sobre el que planteamos estas reflexiones para avanzar en el conocimiento de su técnica, sus temas y los detalles singulares en su manera de hacer, siendo esencial para ello el análisis de los fondos del Museo de Bellas Artes de Córdoba, fundado en 1844 y cuyo primer conjunto de sesenta dibujos ingresa en 1877 y entre los que ya se citan dibujos de Reinoso ${ }^{4}$.

No es este el lugar idóneo para hacer la catalogación de sus diseños, pues aquí se plantea una aproximación a su manera de hacer, a la repetición de modelos y a los diferentes temas que plasma en ellos, analizando sus influencias y su

${ }^{2}$ Palencia Cerezo, 2009: 35-46.

${ }^{3}$ Palomino, 1947: 258.

${ }^{4}$ Para la historia de esta colección, véase, básicamente, García de la Torre, 1997; 2006; 2009; 2011. 
peculiar manera de firmar y de trazar algunos detalles que, en determinadas ocasiones a un primer golpe de vista nos hace identificar un dibujo como del maestro granadino.

En sus dibujos usa lápiz, sanguina y pluma parda y grisácea, habitualmente con toques de aguada parda, grisácea y de colores, estando realizados en su gran mayoría sobre papel verjurado con algún ejemplo de papel agarbanzado. Estos soportes y técnicas los repite de manera habitual, siendo ejemplos de ello la Aparición de la Virgen con el Niño a San Juan Nepomuceno ${ }^{5}$, en la que usa una aguada parda y violácea, similar a la de uno de los Tres estudios preparatorios para bóvedas ${ }^{6}$, las sanguinas del Santo Ermitaño o la Hoja con estudio de figuras ${ }^{8}$, y las repetidas tintas pardas de diversos Proyectos de retablos 9 .

El análisis de los soportes deja ver algunos ejemplos de filigranas, como en el San Miguel, con tres círculos tangentes rematados por una especie de corona ${ }^{10}$, marcas de agua que también se observan en las dos versiones de la Adoración de los Magos, en las que se aprecia la filigrana con dos círculos tangentes y las letras AB; en la Inmaculada con San Juan de la Cruz, con una marca de agua de tres círculos tangentes rematados por una corona, llevando insertas en su interior diversas letras; o en el caso de San Francisco Solano, en que solo se aprecian los restos de dos círculos tangentes con uno más pequeño en su parte interior. En el caso de Santa Bárbara solo tiene los fragmentos de círculos tangentes; en el Proyecto para el remate de un retablo con la Alegoría de la Venerable Orden Tercera, una filigrana de uso bastante común con pequeñas variantes en los tres círculos tangentes rematados por una corona, llevando insertos en su interior una cruz el superior, las letras "oa" el central y un trazo similar a una "n" el inferior; y la Visitación, cuya marca de agua repite dos círculos tangentes con unos trazos no identificados en su interior ${ }^{11}$. Marcas de agua o filigranas de uso generalizado en muchos soportes de dibujos, grabados, partituras musicales, documentos, etc., como las de los tres círculos o esferas tangentes con letras, círculos, cruces o animales en su interior rematados por una cruz o una corona, que además en algún caso coincide con las que aparecen en papeles utilizados en Córdoba por Antonio del Castillo y que son usadas, con variantes, desde el siglo XIV en papeles procedentes de Italia, Francia o España, según detalla Briquet, manteniendo Balmaceda cómo en

\footnotetext{
5 Madrid, Colección Juan Abelló, Álbum Alcubierre.

${ }^{6}$ Florencia, Galleria degli Uffizi, Gabinetto dei disegni e stampe. Inv ${ }^{\circ} 6869$ A y 10525 S.

${ }^{7}$ Córdoba, Museo de Bellas Artes. $N^{\circ} \mathrm{R}^{\circ}$ CE $0911 \mathrm{D}$.

${ }^{8}$ Londres, Courtauld Institute of Art, Witt Collection. Inv ${ }^{\circ}$ D.1952.RW.4204.

${ }^{9}$ La mayoría de ellos en Córdoba, Museo de Bellas Artes. N ${ }^{\circ} \mathrm{R}^{\circ} \mathrm{CE} 1036 \mathrm{D}, \mathrm{CE} 1038$

D, CE 1058 D o CE 1061 D.

${ }^{10}$ Madrid, Colección Juan Abelló, Álbum Alcubierre.

11 Todos estos en Córdoba, Museo de Bellas Artes. $N^{\circ} \mathrm{R}^{\circ}$ CE 0869 D, CE 0890 D, CE 0997 D, CE 0906 D y CE 0910 D.
} 
España, principalmente en Cataluña, imitan o se inspiran en las filigranas genovesas de tres círculos manteniéndose su uso incluso durante el siglo XVIII ${ }^{12}$.

Una de sus peculiaridades es la detallada manera de firmar y fechar sus dibujos, cosa nada frecuente en otros maestros. Muchos de ellos están firmados y fechados, mostrando generalmente gran detalle, como demuestra la inscripción "ANTONIUS GARCIA/ DEPIXIT/ ANNO 1646" de la Portada del Álbum de Antonio García Reinoso ${ }^{13}$, que además lleva las inscripciones "DE PICTURA INSIGNI/ INICIA" y "Pictura ómnium artium/ inbentris". En otros casos, las firmas son "Antt ${ }^{\circ}$ Garcia Rs ${ }^{\circ}$ 164(3) (8?)" en los Ángeles con relicarios ${ }^{14}$; "Antt" Garcia de Reinoso. Noviembre 1647" en la Hoja con estudio de figuras de Londres ${ }^{15}$; el Santo ermitaño ${ }^{16}$, firmado y fechado de manera muy detallada como "At ${ }^{\circ}$ Ga Rss. dire. 20 de 1650"; el San Sebastián y dos figuras teatrales (?) ${ }^{17}$, fechado en "febrer ${ }^{\circ}, 29$ de $1654 \mathrm{a}^{0}$ "; los Estudios de cabezas y tres ángeles ${ }^{18}$, donde solo consta la fecha "Sre, 27 de 1655"; el Proyecto de remate para un retablo con alegoría de la Venerable Orden Tercera ${ }^{19}$, con las firmas "D Ant ${ }^{\circ}$ Garcia Reinoso" y "A. Ga. Rss 18 de Nre. 1663"; o las dos versiones de la Adoración de los Magos ${ }^{20}$, con las firmas "Reinoso Dre 24 de 1670" y "A ${ }^{\circ}$ Garcia Reinoso en 3...1670". Detalles similares repite en "At $\mathrm{t}^{\mathrm{O}} \mathrm{G}^{\mathrm{a}}$ Reinoso 16 dre. de 1671 " y "Garcia Reinoso diciembre 26 año de 1671" en los Tres estudios preparatorios para bóvedas ${ }^{21}$, o la fecha de "1677" -año de su muerte- incluida en la Aparición de la Virgen con el Niño a San Juan Nepomuceno de la Colección Abelló.

Sus diseños se pueden dividir, básicamente, en cuatro bloques temáticos. Por un lado, los temas mitológicos, muy poco habitual en el dibujo seiscentista español, como la Hoja con estudio de figuras - a veces publicado como Personajes con el dios Marte- de Londres ${ }^{22}$, de 1647, de calidad excepcional y rasgos que se repiten en parte de sus dibujos figurativos. Acompañan a Marte, Venus y $\mathrm{Cu}$ pido y otras figuras posiblemente identificadas con Diana y Acteón y Apolo. Los artistas barrocos españoles tienen fuentes de inspiración constatadas en estampas

${ }^{12}$ Briquet, 1907: 217-219, cat. No 3.241 a 3.270. Balmaceda, 2005: 105, 131-135, 140$145,152-153,218-219,230$ y $239-308$, cita o reproduce numerosas filigranas de tres círculos o esferas, pero ninguna coincide con las aquí citadas.

${ }_{13}$ Madrid, Biblioteca Nacional de España. Inv ${ }^{\circ}$ DIB/18/1/876/1. Un minucioso estudio de este álbum se encuentra en Rodríguez, 1991: 313-363.

${ }^{14}$ Córdoba, Museo de Bellas Artes. $N^{\circ} \mathrm{R}^{\circ} \mathrm{CE} 0864 \mathrm{D}$.

15 Londres, Courtauld Institute of Art, Witt Collection. Inv ${ }^{\circ}$ D.1952.RW.4204.

${ }^{16}$ Córdoba, Museo de Bellas Artes. N ${ }^{\circ} \mathrm{R}^{\circ}$ CE 0911 D.

${ }_{17}$ Madrid, Real Academia Española, Colección Rodríguez-Moñino Brey. Inv ${ }^{\circ}$ DRM 746.

${ }_{18}$ Florencia, Galleria degli Uffizi, Gabinetto disegni e Stampe. Inv ${ }^{\circ} 6773$ S.

${ }_{19}$ Córdoba, Museo de Bellas Artes. $\mathrm{N}^{\circ} \mathrm{R}^{\circ} \mathrm{CE} 0906 \mathrm{D}$.

${ }^{20}$ Córdoba, Museo de Bellas Artes. N $\mathrm{N}^{\circ}$ CE 0869 D y CE 0912 D.

${ }^{21}$ Florencia, Galleria degli Uffizi, Gabinetto disegni e Stampe. Inv ${ }^{\circ} 6869$ A y 10525 S.

${ }^{22}$ Londres, Courtauld Institute of Art, Witt Collection. Inv ${ }^{\circ}$ D.1952.RW.4204. 
flamencas o italianas, y un ejemplo más se añade en algunas figuras de este diseño de Reinoso con grabados del alemán Heindrik Goltzius (1558-1617) y, especialmente, con el dibujo a sanguina del potente dios guerrero Marte ${ }^{23}$, cuya iconografía tiene concordancias en ambos diseños, y con el de Juno de Abraham Bloemaert (1566-1651), maestro que también tiene una fuerte influencia en bastantes dibujos de Castillo, repitiendo así las coincidencias entre ambos maestros andaluces $^{24}$ (Figura 1). Este interés por la mitología se repite en una de las hojas de Tres estudios preparatorios para bóvedas de Florencia, de 1671, que pueden identificarse de arriba abajo en cada uno de los bocetos con las leyendas de Sexto Tarquinio y Lucrecia, Hércules, Neso y Deyanira y Dido y Eneas.

Muy significativos son sus proyectos decorativos y arquitectónicos, en los que se deben tener en cuenta sus vinculaciones con Alonso Cano (1601-1667) y Sebastián Herrera Barnuevo (1619-1671) ${ }^{25}$. Esos proyectos se pueden agrupar en diseños ornamentales y de mobiliario litúrgico y en trazas de retablos, abundando en ambos elementos comunes que reflejan su manera de hacer y sus influencias, que confirman la cita de Palomino sobre la variada tipología de sus dibujos.

De gran sutileza son sus Ángeles con relicario de 1643 o $1648^{26}$ (Figura 2), compuestos en dos grupos que sostienen sendos relicarios, que podrían también ser interpretados como espejos, manifestando tanto los ángeles como el sombreado entrecruzado una fuerte vinculación con Castillo, aunque Reinoso en esa fecha aún no estaba en Córdoba. La Cartela decorativa con ángeles atlantes ${ }^{27}$ podría ser una traza para una decoración de yeserías que albergaría un lienzo en la parte central. Elementos ornamentales que repite o reinterpreta en la Tarja y cartela decorativa ${ }^{28}$ con cinco opciones de composición en el mismo soporte, que Delfín Rodríguez considera bajo la influencia del manierismo florentino a través de grabados de Herrera el Viejo, además del influjo granadino que llega a Córdoba con José Granados de la Barrera y Melchor de Aguirre, quien desde 1673

${ }^{23}$ Besançon, Musèe des Beaux-Arts et d'Archèologie.

${ }^{24}$ El análisis más detallado de este importante dibujo se hace en Veliz, 2011: 182-185. El de la influencia de Bloemaert en Castillo puede verse en García de la Torre/Navarrete Prieto, 2016.

${ }^{25}$ Estos diseños han sido básicamente analizados por Manteca, 1977. Müller, 1999; 2006. Pérez Sánchez, 1972; 1980; 1986. Rodríguez, 1991. García de la Torre, 1997; 2001a; 2001b; 2005; 2006; 2008; 2015; 2016, por lo que salvo en algún caso no se citara la bibliografía de cada dibujo de manera específica.

${ }^{26}$ No queda claro el último número de la fecha, de ser 1643 sería el primer dibujo fechado que se conoce del maestro, mientras que si fuera 1648, habría que situarlo tras el Álbum de García Reinoso de 1646 y la Hoja con estudios de figuras de 1647 y en el mismo año que la Asunción de la Virgen.

27 Ambos en Córdoba, Museo de Bellas Artes. $\mathrm{N}^{\circ} \mathrm{R}^{\circ}$ CE 0864 D y CE 0863 D.

${ }^{28}$ Madrid, Biblioteca Nacional de España. Inv ${ }^{\circ} \mathrm{DIB} / 16 / 40 / 13$. 
trabaja en Cabra (Córdoba) siguiendo trazas de Granados ${ }^{29}$. No podemos olvidar que allí vivió muchos años Reinoso, aunque en esas fechas ya debía estar afincado en Córdoba, tras su paso por Jaén y Granada.

Importante es también el Diseño para una custodia, atribuido al maestro por Priscilla Müller ${ }^{30}$ y muy vinculado a dibujos de Herrera Barnuevo, tanto en la técnica como en la manera de usar la pluma y en el uso de aguadas de colores. Las concomitancias con Herrera Barnuevo llevan una vez más a la vinculación de Reinoso y Cano, fundamentalmente en los proyectos decorativos y de retablos o, como en este caso, de mobiliario litúrgico. Así se observa en el uso de un trazo muy determinado y de aguadas de colores, como se constata en este dibujo de Nueva York, en sus Tres estudios preparatorios para bóvedas de los Uffizi y en la Aparición de la Virgen con el Niño a San Juan Nepomuceno del Álbum Alcubierre $^{31}$, que lo pone en relación con el Proyecto de decoración festiva con volutas ornamentales coronada por la figura de la Fama ${ }^{32}$ atribuido a Alonso Cano o el Proyecto de baldaquino para la capilla de San Isidro de la iglesia de San Andrés de Madrid, el Altar y la Decoración de entrepaños ${ }^{33}$ de Herrera Barnuevo, que presentan detalles comunes entre dibujos de Cano, Herrera Barnuevo y García Reinoso. Un ejemplo más de sus trazas de mobiliario litúrgico es el Proyecto de urna para el Santo Entierro (Figura 3) que estuvo erróneamente catalogado como Arca de reliquias de estilo renacimiento, pues se aprecia perfectamente la imagen de Cristo yacente en su interior; los restos de unos trazos que pueden identificarse con la firma de Reinoso, la hoja canesca y los característicos angelitos de las esquinas y el remate lo relacionan con sus dibujos, incluyendo distintas opciones de las trazas de los soportes de esta urna sobre parihuelas diseñada posiblemente para ser llevada a la madera, incluyendo en la parte inferior el pitipié para la escala del proyecto, al igual que en el Proyecto para el remate de un retablo con la Alegoría de la Venerable Orden Tercera. La misma estética que puede reflejarse en el Facistol que se le atribuye, aunque sus trazos son menos contundentes que los de otros de sus diseños de mobiliario, lo que puede poner en entredicho su autoría. Muchos de estos detalles ornamentales se repiten en el Proyecto de templete para la Virgen del

${ }^{29}$ Rodríguez, 1991: 56. Raya, 1987: 52-54 y 221.

${ }^{30}$ Nueva York, Hispanic Society of America. El dibujo se adquiere en 1976 como de Sebastián Herrera Barnuevo, siendo adscrito al maestro granadino en Müller, 2006: 176178, y publicado de nuevo por Banner, 2010: 100-102.

${ }_{31}$ Madrid, Colección Juan Abelló, Álbum Alcubierre.

${ }^{32}$ Hamburgo, Kunsthalle. Kupferstichkabinett. Inv 38502.

33 Estos tres últimos en Madrid, Biblioteca Nacional de España. Inv ${ }^{\circ}$ DIB/13/2/80, DIB/16/35/10 y DIB/16/37/10 respectivamente. 
Rosario, diseñado para ser ejecutado en madera o plata en la tradición de las andas marianas frecuentes en el XVII español ${ }^{34}$.

Una destacada significación entre este grupo de dibujos arquitectónicos y ornamentales tiene la Portada del Álbum de García Reinoso ${ }^{35}$, fechada en 1646 y concebida a modo de retablo con alegorías artísticas, con una estructura clásica de cuerpos y calles donde ubica diferentes figuras alegóricas, y otras dos pintando o dibujando, y paletas y pinceles alusivos al arte de la pintura que ensalza en las inscripciones "De pictura insigni inicia" y "Pictura omnium artium inbentris", usando un esquema también usual en el diseño de portadas de libros. El álbum está compuesto por sesenta y nueve dibujos españoles e italianos del XVI al XVIII relacionados con arquitectura, pintura, escultura, orfebrería y elementos ornamentales, entre los que hay varios de Cano, distintos anónimos andaluces, alguno de Herrera Barnuevo, treinta y cinco de Giovanni Battista Montano (15341621) y el conocido diseño de la Fachada de la catedral de Cádiz de Vicente Acero (activo 1708-1744) (Figura 4).

Muy interesante es el citado Proyecto para el remate de un retablo con la Alegoría de la Venerable Orden Tercera de 1663, en el que incluye el pitipié para la escala y "baracas de llana de 4 palmos" y traza dos opciones compositivas en sendas calles laterales decoradas con profusión de frutas, algunas similares a las de la bandeja de frutas al dorso de la Asunción de la Virgen ${ }^{36}$, mientras la calle central está ocupada por el boceto para una pintura de compleja iconografía relacionada con el Buen Pastor, el Alma Cristiana y la Adoración del Santísimo Sacramento, especialmente vinculada con la Venerable Orden Tercera Franciscana, como la del retablo de la parroquia de San Francisco y San Eulogio de la Axerquía de Córdoba, que se repite con variables en composición y título en las Visiones celestiales de la iglesia de San Francisco en Baena (Córdoba), la Alegoría de la Venerable Orden Tercera de la iglesia de San Francisco en Priego de Córdoba o el Rebaño del Buen Pastor y la más perfecta esclavitud de Jesús Sacramentado en el convento de franciscanas descalzas de Salamanca.

Interés por diversos motivos compositivos, temas y color presentan sendas hojas con Tres estudios preparatorios para bóvedas ${ }^{37}$, de 1671, realizados para proyectos no identificados en seis estudios con doble opción de diseño en sus respectivos laterales y diferentes escenas narrativas con temas mitológicos, barcos, ángeles, elementos geométricos y vegetales o frutales, evocando detalles ornamentales de cartelas y tarjas manieristas italianas y los angelitos de Antonio del Castillo y repitiendo detalles de otros de sus dibujos. Ambos refuerzan el

${ }^{34}$ Estos cuatro últimos en Córdoba, Museo de Bellas Artes. $N^{\circ} \mathrm{R}^{\circ} \mathrm{CE} 1055 \mathrm{D}, \mathrm{CE}$ 0906 D, CE 1037 D y CE 1059 D.

${ }_{35}$ Madrid, Biblioteca Nacional de España. Inv ${ }^{\circ}$ DIB/18/1/876/1.

${ }^{36}$ Córdoba, Museo de Bellas Artes. $N^{\circ} \mathrm{R}^{\circ}$ CE $0994 \mathrm{D}$.

${ }^{37}$ Florencia, Galleria degli Uffizi, Gabinetto disegni e Stampe. Inv ${ }^{\circ} 6869$ A y 10525 S. 
reconocimiento de Reinoso para el diseño arquitectónico y ornamental en el barroco español y corresponden a posibles ensayos para la decoración de yeserías muy frecuentes en el barroco andaluz y que, en Córdoba, siguen una tradición que evoluciona desde el renacimiento hasta el barroco dieciochesco con numerosos ejemplos en bóvedas, cúpulas y camarines ${ }^{38}$.

Importantes para avanzar en el conocimiento de Reinoso dibujante son diversos proyectos para retablos, como los titulados Proyecto de retablo con Crucificado y Proyecto de retablo con custodia ${ }^{39}$ (Figura 5), en los que se ha trazado el lateral izquierdo de un retablo con similar lenguaje formal y detalles de hoja canesca y pilastras y basamentos cajeados, proliferación de angelitos y claras vinculaciones con dibujos arquitectónicos y decorativos de su paisano Alonso Cano y del madrileño Sebastián Herrera Barnuevo, discípulo y colaborador de Cano desde su llegada a Madrid y cuyos primeros dibujos se fechan a partir de 1649, casi en los mismos años que los primeros de Reinoso. Quedan por delimitar más detalles de esta conexión entre los tres artistas y aclarar el equívoco que aún puede detectarse en algunas atribuciones de autoría, ya que a veces es difícil apreciar esta diferencia entre Reinoso y Herrera partiendo de la fuente común de Cano añadida a sus aportaciones personales. Este el caso del Proyecto de retablo con San Miguel $^{40}$, considerado en antiguos inventarios del museo de García Reinoso y vinculado con algún retablo de Cano, y más recientemente atribuido al ámbito de Sebastián Herrera Barnuevo, sobre todo a partir de la publicación por Priscilla Müller de un Proyecto de altar con el Ángel de la Guarda, realizado por Cano entre 1658 y 1661, considerando la hispanista norteamericana el dibujo de Córdoba una versión perfeccionada del de Nueva York, realizada por el propio Alonso Cano o un seguidor del mismo o quizás de su discípulo y ayudante Herrera Barnuevo ${ }^{41}$.

Muy vinculado a su manera de dibujar y con grandes posibilidades de ser del maestro es el Proyecto de retablo con pájaros ${ }^{42}$ que a veces he considerado de un anónimo andaluz del siglo XVII, conocedor de los recursos formales de Alonso Cano, y que sería realizado para un convento dominico, como indica el escudo de

${ }^{38}$ Hasta hace pocos años solo se había publicado el diseño de las bóvedas más sencillas, mientras en Navarrete Prieto/García de la Torre, 2008: 152, 155, 156, 193 y 201, se analizaron ambos diseños (Inv 6869 A y 10525 S). Siendo, además, las referencias básicas para ambos Pérez Sánchez, 1972: 17, 91-92, lám. 75, nº 100; 1980: 70-71; 1986: 310. García de la Torre, 1997: 105. Müller, 2006: 175. Navarrete Prieto/Pérez Sánchez, 2009: 150. García de la Torre, 2015: 193 y 201; 2016: 371-373.

39 Ambos en Córdoba, Museo de Bellas Artes. $\mathrm{N}^{\circ} \mathrm{R}^{\circ} \mathrm{CE} 1058 \mathrm{D}$ y CE 1036 D.

${ }^{40}$ Córdoba, Museo de Bellas Artes. $\mathrm{N}^{\circ} \mathrm{R}^{\circ} \mathrm{CE} 1038 \mathrm{D}$.

${ }^{41}$ Nueva York, Hispanic Society. Müller, 1999: 445-447. García de la Torre, 2001a: 318-319; 2001b: 12, 15 y 30-31. Müller, 2006: 127-129. García de la Torre, 2007: 300-301.

${ }^{42}$ Córdoba, Museo de Bellas Artes. $\mathrm{N}^{\circ} \mathrm{R}^{\mathrm{o}} \mathrm{CE} 1061 \mathrm{D}$. 
la orden con su característica cruz florenzada, que corresponde a la traza de un retablo-marco, posiblemente para albergar en su hueco central un lienzo de gran formato.

Las anteriores reflexiones vinculan el dibujo cordobés y granadino del siglo XVII, que llega a García Reinoso pasando por Alonso Cano, básicamente en sus trazas de retablos y elementos arquitectónicos y ornamentales, en un lenguaje formal común a los diseños de Cano, Reinoso y Herrera, además de la posible influencia de Melchor de Aguirre y José Granados, artistas granadinos muy vinculados a Córdoba.

Entre sus numerosos dibujos religiosos deben señalarse la Asunción de la Virgen, firmada y fechada en $1648^{43}$, o el Santo Ermitaño ${ }^{44}$, de 1650 , a sanguina, potenciando los perfiles de la figura y difuminando su interior para resaltar la monumental imagen del santo. Un detallado dibujo, poco conocido, es el San Sebastián y dos figuras teatrales (? ${ }^{45}$, de 1654 , con trazos muy comunes a otros diseños de Reinoso y una iconografía en la que claramente se puede identificar a San Sebastián, mientras las dos restantes han sido asociadas a personajes del teatro por sus vestimentas a la usanza del siglo XVI y sus amaneradas $\operatorname{poses}^{46}(\mathrm{Fi}-$ gura 6). Igualmente, poco conocidos son los Estudios de cabezas y tres ángeles ${ }^{47}$, de 1655, que Alonso del Moral considera bajo la influencia de grabados manieristas nórdicos, sin olvidar al observarlos los trazos de sombreados paralelos que en Córdoba hacía Antonio del Castillo y en Sevilla Herrera el Viejo. Mas tardíos son el inédito San Lucas pintando a la Virgen $^{48}$, firmado en 1664, y en todo coincidente con los trazos habituales del maestro (Figura 7), y el San Miguel arcángel, fechado en $1665^{49}$.

Tiene, además, dos versiones de la Adoración de los $\operatorname{Magos}^{50}$, ambas de 1670, ambientadas en una arquitectura de reminiscencias italianas y gran profusión de personajes, con evidente recuerdo de estampas de Rubens, que Pérez Sánchez

${ }^{43}$ Córdoba, Museo de Bellas Artes. No $\mathrm{R}^{\circ}$ CE 0994 D. La fecha se cita solo en los inventarios del museo del siglo XIX, habiendo desaparecido parcialmente por daños sufridos en fecha desconocida. Versiones de esta Asunción de la Virgen se han encontrado en una colección norteamericana en 2014 y en el comercio de arte madrileño en 2019.

${ }^{44}$ Córdoba, Museo de Bellas Artes. $N^{\circ} \mathrm{R}^{\circ} \mathrm{CE} 0911 \mathrm{D}$.

${ }^{45}$ Madrid, Real Academia Española, Colección Rodríguez-Moñino Brey. Inv ${ }^{\circ}$ DRM 746.

${ }^{46}$ Blas/Ciruelos/Matilla, 2002: 58-60 y 359.

${ }^{47}$ Florencia, Galleria degli Uffizi, Gabinetto disegni e Stampe. Inv ${ }^{\circ} 6773$ S. Alonso del Moral, 2016. 374.

${ }^{48}$ España, Colección privada.

49 Madrid, Colección Juan Abelló, Álbum Alcubierre.

${ }^{50}$ Córdoba, Museo de Bellas Artes. N ${ }^{\circ} \mathrm{R}^{\circ}$ CE 0869 D y CE 0912 D. 
considera "habilísimamente reinterpretadas, con evidente personalidad" 51 . De fecha similar se creen los Estudios de ángeles de Florencia, de antiguo considerado como de Francesco Francanzano (1612-1656), e incluso vinculado en la Galleria degli Uffizi en algún momento con Antonio del Castillo, con cuya técnica es indudable su relación. Es un curioso repertorio de ángeles niños muy característicos de su estilo, coincidiendo la grafía y manera de estar firmado con las de Reinoso; debía corresponder a un boceto para un encargo del duque de Osuna, como consta en una inscripción al dorso ${ }^{52}$. El último dibujo fechado de Reinoso es la Aparición de la Virgen con el Niño a San Juan Nepomuceno, anteriormente identificado como San Cayetano ${ }^{53}$, de 1677, de gran intensidad cromática en el uso conjunto de aguadas pardas y violáceas en potentes masas volumétricas.

De fecha indeterminada son el San Ildefonso recibiendo la casulla de la Vir$\mathrm{gen}^{54}$, muy cercano por sus trazos paralelos a algunos diseños de Antonio del Castillo; la Apoteosis de San José55; y las dos versiones de la Inmaculada con San Juan de la $\mathrm{Cruz}^{56}$, que tienen en común la inclusión de diseños de cartelas y escudos, con diferentes modelos y propuestas insertas entre las escenas religiosas, muy característica de la forma de trabajar del maestro, en un tratamiento similar al que propone en algunas de sus trazas de retablos, en las que ofrece variantes de sus elementos decorativos. No se conocen referencias pictóricas sobre las composiciones de Córdoba, mientras que, en relación con la Apoteosis de San José, Palomino describe un lienzo de gran formato y similar composición y temática del dibujo madrileño en la iglesia de los Capuchinos de Andújar (Jaén) ${ }^{57}$.

Un complejo San Diego de Alcalá en pie, sosteniendo la Cruz y con las rosas recogidas en el hábito ${ }^{58}$ fue atribuido por Angulo y Pérez Sánchez al círculo de Zurbarán, citando que estuvo antes considerado del círculo de Murillo, mientras Brown lo considera del propio Murillo, sin desvincularlo de algún artista de su entorno, y Mena lo cree de García Reinoso. Del mismo hay una versión en el Museo de Bellas Artes de Córdoba, citado en ocasiones como de Antonio García

${ }^{51}$ Pérez Sánchez, 1986: 310. Una tercera versión se conserva en el Museo de Bellas Artes de Córdoba, $\mathrm{N}^{\circ} \mathrm{R}^{\circ} \mathrm{DJ} 1419 \mathrm{D}$, fechada el 18 de octubre de 1704 y con la inscripción "RIBASCO. F", copiando una de las versiones del maestro granadino, recogido en Palencia, 2007: 21 y 80 .

${ }^{52}$ Florencia, Galleria degli Uffizi, Gabinetto disegni e Stampe. Inv ${ }^{\circ} 7901$ S. Alonso del Moral, 2016: 375.

${ }_{53}$ Madrid, Colección Juan Abelló, Álbum Alcubierre.

${ }^{54}$ Londres, Courtauld Institute of Art, Witt Collection. Inv ${ }^{\circ}$ D.1952.RW.1482.

${ }_{55}$ Madrid, Biblioteca Nacional de España. Inv ${ }^{\circ} \mathrm{DIB} / 15 / 3 / 2$.

${ }^{56}$ Córdoba, Museo de Bellas Artes. $N^{\circ} \mathrm{R}^{\circ}$ CE 0932 D y CE 0890 D.

57 Palomino, 1947: 258.

${ }^{58}$ Hamburgo, Kunsthalle, Kupferstichkabinett. Inv ${ }^{\circ}$ 38593. Córdoba, Museo de Be1las Artes. N ${ }^{\circ}{ }^{\circ}$ CE 1077 D. Angulo/Pérez Sánchez, 1985: 61, plate LXXIII, 251. Brown, 1976: 64; 2012: 50-51. Mena, 2014: 103; 2015: 600-603. 
Reinoso o incluso de Diego Monroy (1790-1857), que con frecuencia copió con maestría algunas pinturas cordobesas del XVII. Actualmente ambos diseños pueden considerarse de Reinoso, ya que, en el de Córdoba, la identificación de las letras "Rein [...]" lleva a pensar en el maestro granadino, aunque sea de menor calidad que el de Hamburgo y considerado por Mena como copia del mismo.

Varias atribuciones al maestro ponen de manifiesto el flujo de las citadas influencias y coincidencias técnicas y temáticas en diversos diseños andaluces, bien como en este caso entre Córdoba y Sevilla o los mencionados entre Córdoba y Granada. Un claro ejemplo de la dificultad de atribución de nuevo puede hacerse en el San Jerónimo ${ }^{59}$, considerado de Antonio García Reinoso por Müller y de Francisco de Herrera el Mozo (1627-1685) por Pérez Sánchez, y con una forma de hacer igualmente muy cercana a Antonio del Castillo, siendo todos ellos destacados ejemplos de su interesante producción gráfica de temática religiosa. En este mismo sentido puede considerase una Santa Apolonia ${ }^{60}$, fechada en el "Año de 1665 "-el 5 podría ser igualmente un 9-, con las inscripciones "Zurbaran", "10" y "[...] a los estos papeles a $8 \mathrm{Rs}$ ", dibujada bajo claras influencias estilísticas de Antonio del Castillo y del propio Antonio García Reinoso, tanto en la forma de hacer el sombreado cercano a Castillo como en la grafía de la fecha coincidente con algunos trazos de Reinoso. A veces considerado de Reinoso, aunque de menor calidad y de trazo algo distinto a la mayoría de sus diseños, es la Tarja ${ }^{61}$, con un abocetado ángel en su parte central, inserta en el Álbum de García Reinoso al dorso de un dibujo de un Candelabro de Giovanni Battista Montano (1534-1621).

La última iconografía a reseñar es una nave llegando a puerto dibujada por Reinoso en el luneto superior de uno de los Tres estudios preparatorios para bóvedas de Florencia, con una profusión decorativa y de aguadas de colores de destacada calidad, firmado el 26 de diciembre de 1671. Los temas de barcos dibujados son bastante inusuales en el ámbito español, con algunos referentes en el pintor Enrique de las Marinas (hacia 1620-hacia 1680) como su Marina ${ }^{62}$, de tradición flamenca, con la inscripción "di Enrico Spagnoletto"; el anónimo español de hacia 1660 de Galeones en la mar desde tierra ${ }^{63}$; o el Micer Ambrosio de Bocanegra vence a los ingleses en La Rochelle, dentro de un conjunto de dibujos de batallas

${ }^{59}$ Madrid, Biblioteca Nacional de España. Inv ${ }^{0}$ DIB 15/2/36. Pérez Sánchez/Navarrete Prieto, 1995: 170-171. Müller, 1997: 300.

${ }^{60}$ Madrid, Real Academia Española, Colección Rodríguez-Moñino Brey. Invo DRM 828.

${ }^{61}$ Madrid, Biblioteca Nacional de España. Invo Tarja DIB/18/1/896/2 y Candelabro DIB/18/1/896/1.

${ }^{62}$ París, Musée du Louvre, Dèpartament des arts graphiques. Inv ${ }^{\circ} 18421$. Boublie, 1991: 230-231.

${ }^{63}$ Florencia, Galleria degli Uffizi, Gabinetto disegni e Stampe. Inv 10407 S. Navarrete Prieto, 2016b: 261. 
vinculadas a la casa ducal de Fernán Núñez, atribuido en 2017 a José Jiménez Donoso (hacia 1632-1690) y Matías de Torres (1635-1711) ${ }^{64}$.

Señalados estos bloques iconográficos, se aprecia cómo en algunos de ellos hay una conjunción temática en la que las trazas arquitectónicas y decorativas sirven de soporte visual para escenas de variada composición. Ejemplos de ello se encuentran en los mencionados Proyectos de retablos, Proyecto de remate para un retablo con alegoría de la Venerable Orden Tercera, Proyecto de andas o templete de la Virgen del Rosario, Proyecto de urna para el Santo Entierro, o las versiones de la Inmaculada con San Juan de la Cruz y en uno de los Tres estudios preparatorios para bóvedas. En todos se pone de manifiesto un personal sistema de trabajo, que confirma lo narrado por Palomino al señalar que García Reinoso "tuvo gran facilidad en la invención, de que dejó gran copia de dibujos que los hacía con extremado primor, de aguadas, pluma, carbón o lápiz, sin contentarse en hacer de un asunto un dibujo, sino muchos y muy diferentes [...] fue también gran arquitecto, e hizo varias trazas para retablos y piezas de platería. [...] Hizo muchas obras públicas en el reino de Jaén”. Décadas después, Ceán Bermúdez cita que el artista "se dedicó a hacer trazas y dibujos para los plateros y tallistas, difundiendo sus ridículos caprichos en los retablos, en los muebles y en las alhajas de oro y plata. [...] Hacía muchos dibujos, pero sin corrección y sin contar con el natural, y los hacía de varios colores" ${ }^{\prime 5}$. De este amplio repertorio se conservan numerosos ejemplos que lo llevan a un merecido reconocimiento en la historia del dibujo español del siglo XVII, aunque se recojan algunas opiniones bien distintas según los gustos estéticos desde el final del barroco a la ilustración, siendo ensalzado por Palomino y casi ridiculizado por Ceán.

En este análisis de sus dibujos se deben considerar los detalles singulares en su manera de hacer, pues constituyen una identificación importante a la hora de analizarlos. Detalles muy personales como los ojos casi siempre iguales, en una especie de medio círculo abiertos en la parte inferior muy visibles en los Estudios de cabezas y tres ángeles ${ }^{66}$, Santa Inés ${ }^{67}$, la Inmaculada ${ }^{68}$ o la Apoteosis de San $J o s e^{6}$, las repeticiones de elementos en retablos y el uso de la hoja canesca y las pilastras y basamentos cajeados que aparecen en el Proyecto de retablo con custodia y el Proyecto de urna para el Santo Entierro ${ }^{70}$, y el potente uso de aguadas

${ }^{64}$ Córdoba, Museo de Bellas Artes. N ${ }^{\circ} \mathrm{R}^{\circ}$ CE 2741 D. García de la Torre, 2008: 165. Palencia Cerezo, 2017: 53-79.

${ }^{65}$ Palomino, 1947: 996. Ceán, 1800: 173-174.

${ }^{66}$ Florencia, Galleria degli Uffizi, Gabinetto dei disegni e stampe. Inv ${ }^{\circ} 6773$ S.

${ }^{67}$ Citado en Brown, 1983: 10-11 y 17, en Londres-París, Colección E. Schapiro.

${ }^{68}$ Londres, Courtauld Institute of Art, Witt Collection. Inv ${ }^{\circ}$ D.1952.RW.4458.

${ }^{69}$ Madrid, Biblioteca Nacional de España. Inv ${ }^{\circ} \mathrm{DIB} / 15 / 3 / 2$.

${ }^{70}$ Ambos en Córdoba, Museo de Bellas Artes. $N^{\circ} \mathrm{R}^{\circ} \mathrm{CE} 1036$ D y CE 1055 D. 
pardas y violáceas de uno de los Tres estudios preparatorios para bóvedas ${ }^{71}$ y la Aparición de la Virgen con el Niño a San Juan Nepomuceno ${ }^{72}$. A pesar de estas singularidades, aún hay atribuciones de dibujos a Antonio García Reinoso que nada tienen que ver con su estilo, atribuciones que deben ir depurándose para avanzar en un mejor conocimiento del maestro.

Al dorso del soporte de varios de sus diseños, se encuentran curiosas anotaciones y apuntes para otras composiciones más o menos detallados, indicando el precio en reales y cuentas, que suponen una interesante aportación para el conocimiento de su trabajo. Citamos algunos ejemplos como los Ángeles con relica$\mathrm{rio}^{73}$, de Córdoba, a cuyo dorso se ha dibujado un Ángel pasionario no vinculado al trabajo de Reinoso, aunque sí con trabajos cordobeses posteriores a la fecha de este dibujo; el Estudios de ángeles ${ }^{74}$, en el que a tinta junto a diversas series de números se lee "la madera y andamio monta 24307", "todo hecho piedra pintado y dorado", "hecho dorado y plomo 9400 Rs" y a otra grafía "don xptobal de morales capllan mayor del Sr. Duque de Osuna" y "A 20Rs cada pliego"; la Asunción de la Virgen, a cuyo dorso ha dibujado a tinta una bandeja de frutas y otra de hortalizas y el fragmento de un caballero vestido a la usanza de la época, además de la firma y fecha el 22 de junio de $1648^{75}$ (Figura 8); el Proyecto de retablo con pájaros $^{76}$, en el que a su dorso traza a tinta un cazador, un angelito, un perro y otro animal de incierta identificación; el San Diego de Alcalá en pie, sosteniendo la Cruz y con las rosas recogidas en el hábito, de Hamburgo ${ }^{77}$, con una figura de San Jerónimo en el desierto al dorso; o el tenue apunte de una cabeza de mujer de un dibujo muy poco conocido de Santa Inés ${ }^{78}$ que presenta las características formas de Reinoso bajo la influencia de Castillo, o los angelitos con símbolos de la letanía lauretana diseñados de manera muy personal al dorso del Ángel Pasionario con paño de la Verónica ${ }^{79}$.

El amplio repertorio de sus dibujos recoge influencias del cordobés Antonio del Castillo, sin olvidar recuerdos técnicos de Herrera el Viejo, el uso que hizo de algunas estampas de Rubens (1577-1640) o su relación con obras del italiano Simone Contarini (1612-1648) en dibujos que le estuvieron atribuidos, como las dos versiones del Descanso en la Huida a Egipto $^{80}$, que aún alejados de su manera

\footnotetext{
${ }^{71}$ Florencia, Galleria degli Uffizi, Gabinetto dei disegni e stampe. Inv 6869 A y $10525 \mathrm{~S}$.

72 Madrid, Colección Juan Abelló, Álbum Alcubierre.

${ }^{3}$ Córdoba, Museo de Bellas Artes. N ${ }^{\circ} \mathrm{R}^{\circ}$ CE 0864 D.

${ }^{74}$ Florencia, Galleria degli Uffizi, Gabinetto dei disegni e stampe. Inv ${ }^{\circ} 7901 \mathrm{~S}$.

75 Córdoba, Museo de Bellas Artes. Nº R ${ }^{\circ}$ CE 0994 D.

${ }^{76}$ Córdoba, Museo de Bellas Artes. $N^{\circ} \mathrm{R}^{\circ} \mathrm{CE} 1061 \mathrm{D}$.

${ }^{77}$ Hamburgo, Kunsthalle, Kupferstichkabinett. Inv 38593.

${ }_{78}$ Londres-París, Colección E. Schapiro. Brown, 1983: 10-11 y 17.

${ }^{79}$ Córdoba, Museo de Bellas Artes. $\mathrm{N}^{\circ} \mathrm{R}^{\circ} \mathrm{CE} 0902 \mathrm{D}$.

${ }^{80}$ Córdoba, Museo de Bellas Artes. N ${ }^{\circ} \mathrm{R}^{\circ}$ CE 1079 D y CE 1080 D.
} 
de dibujar se ha citado en alguna ocasión su autoría, ya que el ser copias de los grabados del italiano podría alejarlo de su tradicional modo de hacer, pues en todo el aspecto general de una de ellas es más cercano a un aguafuerte que a un dibujo. A ello hay que añadir la repetida vinculación con las trazas arquitectónicas y elementos ornamentales de Alonso Cano y de Sebastián Herrera Barnuevo, además de lo que debió aprender junto a su primer maestro Sebastián Martínez, que también trabajó intensamente en Córdoba y cuyas pinturas, algunas de gran calidad, están muy ligadas a la estética de Antonio del Castillo ${ }^{81}$.

Resumimos estas reflexiones considerando a Antonio García Reinoso como un dibujante versátil que con el lápiz, la sanguina, la pluma y la aguada parda o violácea plasma detalladamente escenas mitológicas y religiosas, mobiliario litúrgico, trazas de retablos y elementos ornamentales o decorativos, que asimilan lo aprendido de otros maestros junto a su peculiar manera de dibujar, dejando detallada constancia de la autoría y la fecha en muchos de ellos como un orgulloso dibujante del barroco andaluz.

Fecha de recepción: 30 de octubre de 2019

Fecha de aceptación: 23 de febrero de 2020

\section{BIBLIOGRAFÍA}

Alonso del Moral, Roberto (2016): "Antonio García Reinoso. Estudios de cabezas y tres ángeles y Estudio de ángeles". En: Navarrete Prieto, Benito (dir.): I Segni nel tempo. Dibujos españoles de los Uffizi. Madrid: Fundación Mapfre/ Galleria degli Uffizi, pp. 374-376.

Angulo, Diego/Pérez Sánchez, Alfonso E. (1985): A corpus of Spanish drawings. Volume three. Seville school (1600-1650). London: Harvey Miller.

Balmaceda, José Carlos (2005): La contribución genovesa al desarrollo de la manufactura papelera española. Málaga: Centro Americano de Historiadores del Papel.

Banner, Lisa A. (2010): "Formerly attributed to Antonio Garcia Reinoso. Monstrance design". En: The spanish manner. Drawings from Ribera to Goya. The Frick collection. New York: The Frick Collection, pp. 99-102.

Blas, Javier/Ciruelos, Ascensión/Matilla, José Manuel (2002): “Antonio García Reinoso. San Sebastián y dos figuras teatrales (?) y Anónimo español (siglo XVII). Santa Apolonia”. En: Colección Rodríguez-Moñino Brey. Real

81 Tras el estudio de Manteca Cano, 1977, bastantes dibujos han sido publicados, además de en las mencionadas referencias específicas, en García de la Torre, 1986; 1997; 2001; 2005; 2006; 2007; 2008; 2016. También han sido citados en diversas publicaciones de Mayer, Müller, Pérez Sánchez, López Torrijos, Brown o Capel Margarito. Básicamente, la vinculación de Reinoso con Sebastián Martínez ha sido analizada en Galera Andreu/Serrano Estrella, 2016, y con Antonio del Castillo en Navarrete Prieto/García de la Torre, 2008. 
Academia Española. Dibujos. Madrid: Fundación Cultural Mapfre Vida, pp. 58-60, 89-90 y 359.

Boublie, L. (1991): "Enrique de las Marinas. Marine". En: Dessins espagnols: Maîtres des XVIe et XVIIe siécles. París: Musée du Louvre, pp. 230-231.

Briquet, Charles M. (1907): Les filigranes. Dictionaire historique des marques du papier des leurs apparition vers jusqu'en 1600. Ginebra: W. Kundig \& Fils, tomo I.

Brown, Jonathan (1976): Murillo and his drawings. Princeton: Art Museum, Princeton University.

(1983): "Drawings by Andalusian masters". En: Apotheca, 3, pp. 9-20.

(2012): Murillo. Virtuoso draftsman. New York: Yale University Press/Centro de Estudios Europa Hispánica.

Ceán Bermúdez, Juan Agustín (1800): Diccionario histórico de los más ilustres profesores de las Bellas Artes en España. Madrid: Imprenta de la Viuda de Ibarra, vol. II.

Galera Andreu, Pedro/Serrano Estrella, Felipe (coords.) (2016): Sebastianus. Pintor de Jaén. Sebastián Martínez Domedel (Jaén, 1615-Madrid, 1667). Jaén: Diputación de Jaén/Instituto de Estudios Giennenses.

García de la Torre, Fuensanta, (1984): "Los dibujos barrocos del Museo de Bellas Artes de Córdoba”. En: El Barroco en Andalucía. Córdoba: Universidad de Córdoba/Diputación Provincial de Córdoba, tomo II, pp. 259-264.

(1986): "La pintura barroca en Córdoba". En: Córdoba y su provincia. Sevilla: Ediciones Gever, tomo III, pp. 316-335.

(1991): "El niño en los dibujos del Museo de Bellas Artes de Córdoba". En: Homenaje a Dionisio Ortiz Juárez. Córdoba: Consejería de Cultura y Medio Ambiente de Junta de Andalucía/Diputación Provincial de Córdoba/Ayuntamiento de Córdoba, pp. 69-86.

(1997): Dibujos del Museo de Bellas Artes de Córdoba. Sevilla: Consejería de Cultura de la Junta de Andalucía.

(2001a): "Estilo de Sebastián Herrera Barnuevo. Proyecto de retablo con San Miguel" y "Antonio García Reinoso. Proyecto de urna para el Santo Entierro". En: IV Centenario de Alonso Cano. Espiritualidad y en modernidad artística. Madrid: Consejería de Cultura de la Junta de Andalucía/TF Editores, pp. 318-321.

(2001b): Homenaje a Alonso Cano, Dibujos. Córdoba: Consejería de Cultura de la Junta de Andalucía.

(2005): "Antonio García Reinoso: Bandeja de frutas y hortalizas y un caballero. Inmaculada Concepción y San Juan de la Cruz. Proyecto de retablo con custodia. Ángel pasionario con paño de la Verónica. Proyecto de Retablo con Alegoría de la Venerable Orden Tercera”. En: En torno al Barroco. Fondos del Museo de Bellas Artes de Córdoba. Córdoba: Consejería de Cultura de la Junta de Andalucía/VIMCORSA/Caja San Fernando, pp. 102-109. 
(2006): Dibujar la mirada. Fondos del Museo de Bellas Artes de Córdoba. Burgos: Caja Burgos.

(2007): "Antonio García Reinoso. Proyecto de urna para el Santo Entierro. Sebastián Herrera Barnuevo (atribuido). Proyecto de retablo con san Miguel”. En: Antigüedad y excelencias. Andalucía barroca. Sevilla: Consejería de Cultura de la Junta de Andalucía, pp. 298-301.

(2008): "Antonio del Castillo en el contexto del dibujo andaluz del siglo XVII". En: Navarrete Prieto, Benito/García de la Torre, Fuensanta: Antonio del Castillo, dibujos. Catálogo razonado. Santander: Fundación Marcelino Botín, pp. 109-170.

(2009): "Pasado, presente y futuro de una colección. Los dibujos del Museo de Bellas Artes de Córdoba". En: Ars Delineandi o el arte de dibujar. Una aproximación a las colecciones de dibujo de los museos andaluces. Granada: Museo de Bellas Artes de Granada, pp. 61-73.

(2011): "Inventarios de una colección. Los dibujos del Museo de Bellas Artes de Córdoba". En: Pulchrum, Scripta varia in honorem $M^{a}$ Concepción García Gainza. Pamplona: Universidad de Navarra, pp. 341-347.

(2015): “¿Dibujo de figura, dibujo de ornamentación y dibujo arquitectónico: campos impermeables o entrelazados?: el caso de Córdoba”. En: De Cavi, Sabina (ed.): Dibujo y ornamento. Trazas y dibujos de artes decorativas entre Portugal, España, Italia, Malta y Grecia. Estudios en honor de Fuensanta García de la Torre. Córdoba: Diputación de Córdoba/De Luca Editori d'arte, pp. 189-201.

(2016): "Antonio García Reinoso. Tres estudios preparatorios para retablos (6869A) y Tres estudios preparatorios para retablos (10525S)". En: Navarrete Prieto, Benito (dir.): I Segni nel tempo. Dibujos españoles de los Uffizi. Madrid: Fundación Mapfre/Galleria degli Uffizi, pp. 371-373.

García de la Torre, Fuensanta/Navarrete Prieto, Benito (2016): Antonio del Castillo en la senda del naturalismo. Sevilla: Consejería de Cultura de la Junta de Andalucía.

Manteca Cano, Pilar (1977): El pintor andaluz Antonio García Reinoso. Memoria de licenciatura inédita. Madrid: Universidad Autónoma.

Mena Marqués, Manuela B. (2014): "Antonio García Reinoso. San Diego de Alcalá en pie, sosteniendo la Cruz y con las rosas recogidas en el hábito". En: Hoffmann-Samland, Jens: Dibujos españoles en la Kunsthalle de Hamburgo. Madrid: Museo Nacional del Prado/Kunsthalle de Hamburgo, p. 103, cat. 48. (2015): Bartolomé Esteban Murillo (1617-1682). Dibujos. Catálogo razonado. Santander: Fundación Marcelino Botín.

Müller, Priscilla E. (1997): "Three centuries of sevillian drawing". En: Master Drawings. Nueva York: Master Drawings, vol. 35, nº 3, pp. 299-302. (1999): "Spanish drawings in Valencia and Cordoba". En: Master Drawings. Nueva York: Master Drawings, vol. 37, $\mathrm{n}^{\circ}$ 4, pp. 445-447. 
(2006): Dibujos españoles en la Hispanic Society of America. Del siglo de oro a Goya. Madrid: Museo Nacional del Prado/Hispanic Society of America.

Navarrete Prieto, Benito (2016a): "El triunfo del dibujo español en la Galería de los Uffizi”. En: Navarrete Prieto, Benito (dir.): I Segni nel tempo. Dibujos españoles de los Uffizi. Madrid: Fundación Mapfre/Galleria degli Uffizi”, pp. 13-43. (2016b): "Anónimo español. Galeones en la mar desde tierra". En: Navarrete Prieto, Benito (dir.): I Segni nel tempo. Dibujos españoles de los Uffizi. Madrid: Fundación Mapfre/Galleria degli Uffizi, p. 261.

Navarrete Prieto, Benito/García de la Torre, Fuensanta (2008): Antonio del Castillo (1616-1668). Dibujos. Catálogo razonado. Santander: Fundación Marcelino Botín.

Navarrete Prieto, Benito/Pérez Sánchez, Alfonso E. (2009): Álbum Alcubierre. Dibujos. De la Sevilla ilustrada del Conde del Águila a la Colección Juan Abelló. Madrid: Fundación Arte Hispánico.

Palencia Cerezo, José María (2007): "Secando lágrimas y rellenando huecos. Nuevos fondos para dos décadas". En: García de la Torre, Fuensanta (coord.): Museo de Bellas Artes de Córdoba. Incremento de colecciones, 1986-2006. Córdoba: Consejería de Cultura de la Junta de Andalucía, pp. 13-32.

(2009): "La serie sobre San Fernando de Antonio García Reinoso en la Catedral de Córdoba". En: Archivo Español de Arte, LXXXII, 325, pp. 35-46. (2017): "Linajes y batallas en la vida cotidiana de la nobleza española: el caso de la Casa de Fernán Núñez”. En: Revenga Domínguez, Paula (coord.): Arte barroco y vida cotidiana en el mundo hispánico. Entre lo sacro y lo profano. Córdoba: Universidad de Córdoba, pp. 53-79.

Palomino, Antonio Acisclo (1947): El museo pictórico y escala óptica. Madrid: M. Aguilar editor.

Pérez Sánchez, Alfonso E. (1972): Mostra di disegni spagnoli. Gabinetto disegni e stampe degli Uffizi. Florencia: Galleria degli Uffizi/Leo S. Olschki Editore. (1980): El dibujo español de los siglos de oro. Madrid: Ministerio de Cultura. (1986): Historia del dibujo en España. De la Edad Media a Goya, Madrid: Cátedra.

Pérez Sánchez, Alfonso E./Navarrete Prieto, Benito (1995): Tres siglos de dibujo sevillano. Sevilla: Fundación Fondo de Cultura de Sevilla (FOCUS).

Raya Raya, María Ángeles (1987): Retablo barroco cordobés. Córdoba: Monte de Piedad y Caja de Ahorros de Córdoba, Obra Cultural.

Rodríguez, Delfín (1991): "Álbum de Antonio García Reinoso (siglos XVIXVIII)". En: Dibujos de Arquitectura y Ornamentación de la Biblioteca Nacional. Siglos XVI y XVII, Madrid: Ministerio de Cultura/Biblioteca Nacional, pp. 56, 315-323 y 339.

Ruskin, John (1999): Técnicas de dibujo. Barcelona: Laertes.

Véliz, Zahira (2011): Spanish Drawings in the Courtauld Gallery. Complete catalogue. London: The Courtauld Gallery/Centro de Estudios Europa Hispánica/ Paul Holberton Publishing. 


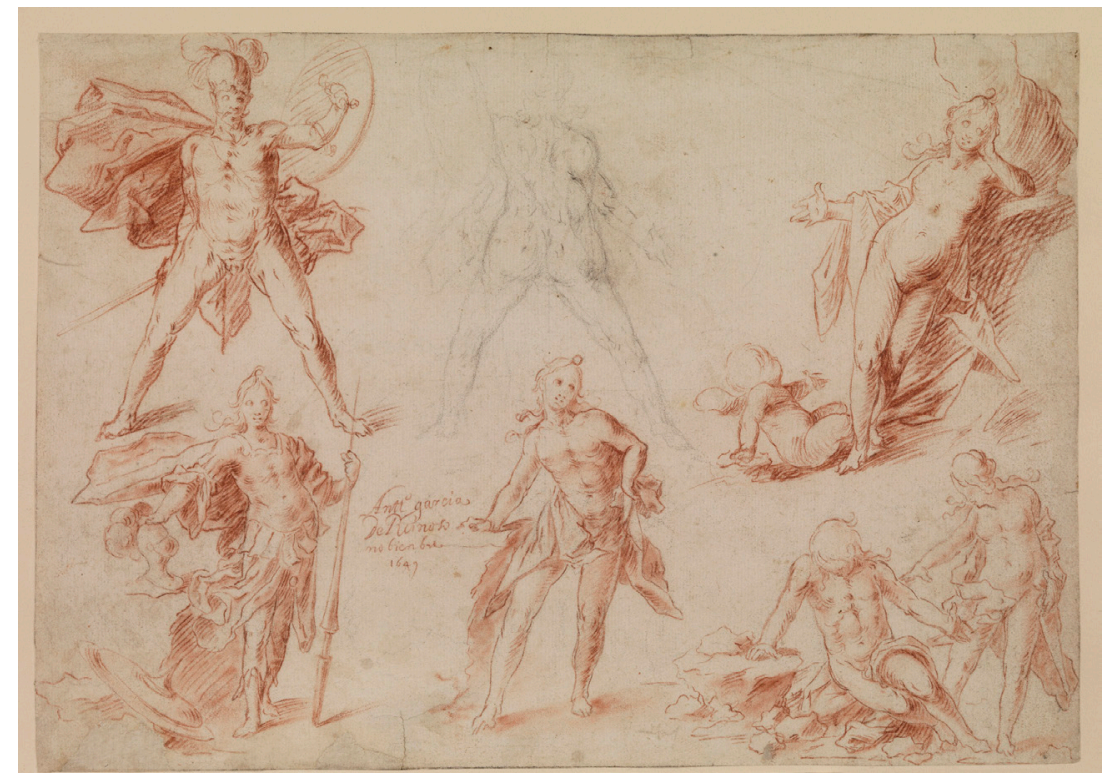

Figura 1. Antonio García Reinoso, Hoja con estudio de figuras, 1650. (C) The Samuel Courtauld Trust, The Courtauld Gallery, London (Invo. D.1952.RW.4204).

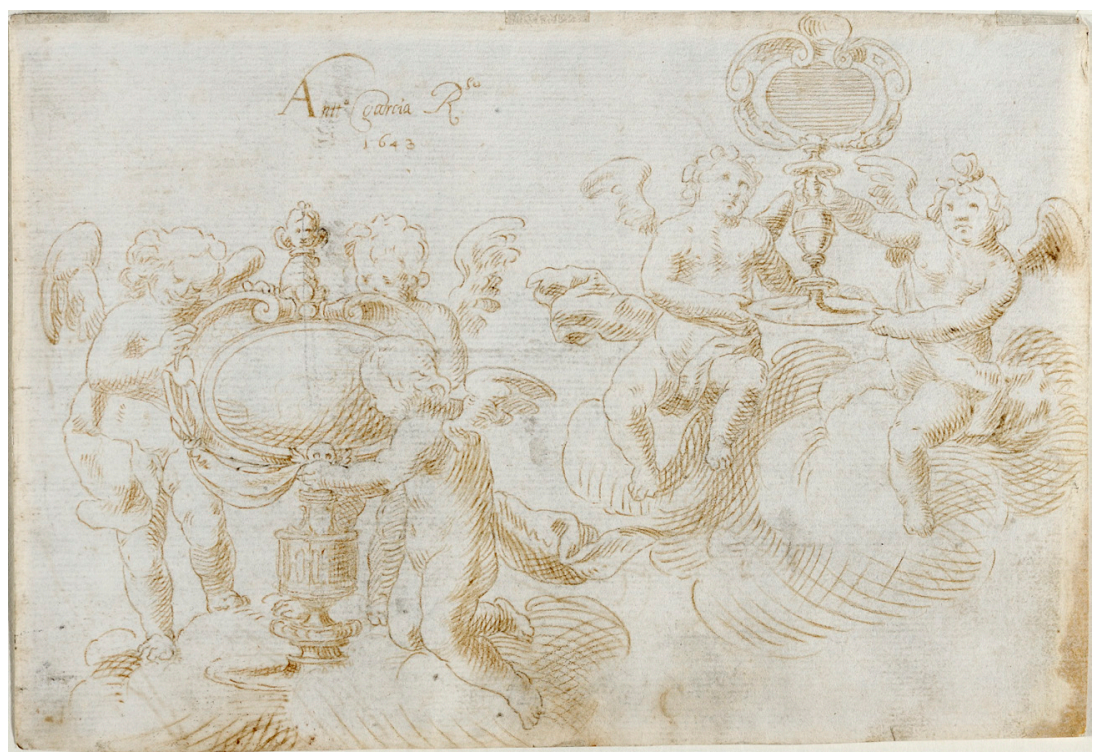

Figura 2. Antonio García Reinoso, Ángeles con relicario, 1643 o 1648, Museo de Bellas Artes de Córdoba ( $\left.{ }^{\circ} \mathrm{R}^{\circ} \mathrm{CE} 0864 \mathrm{D}\right)$. 


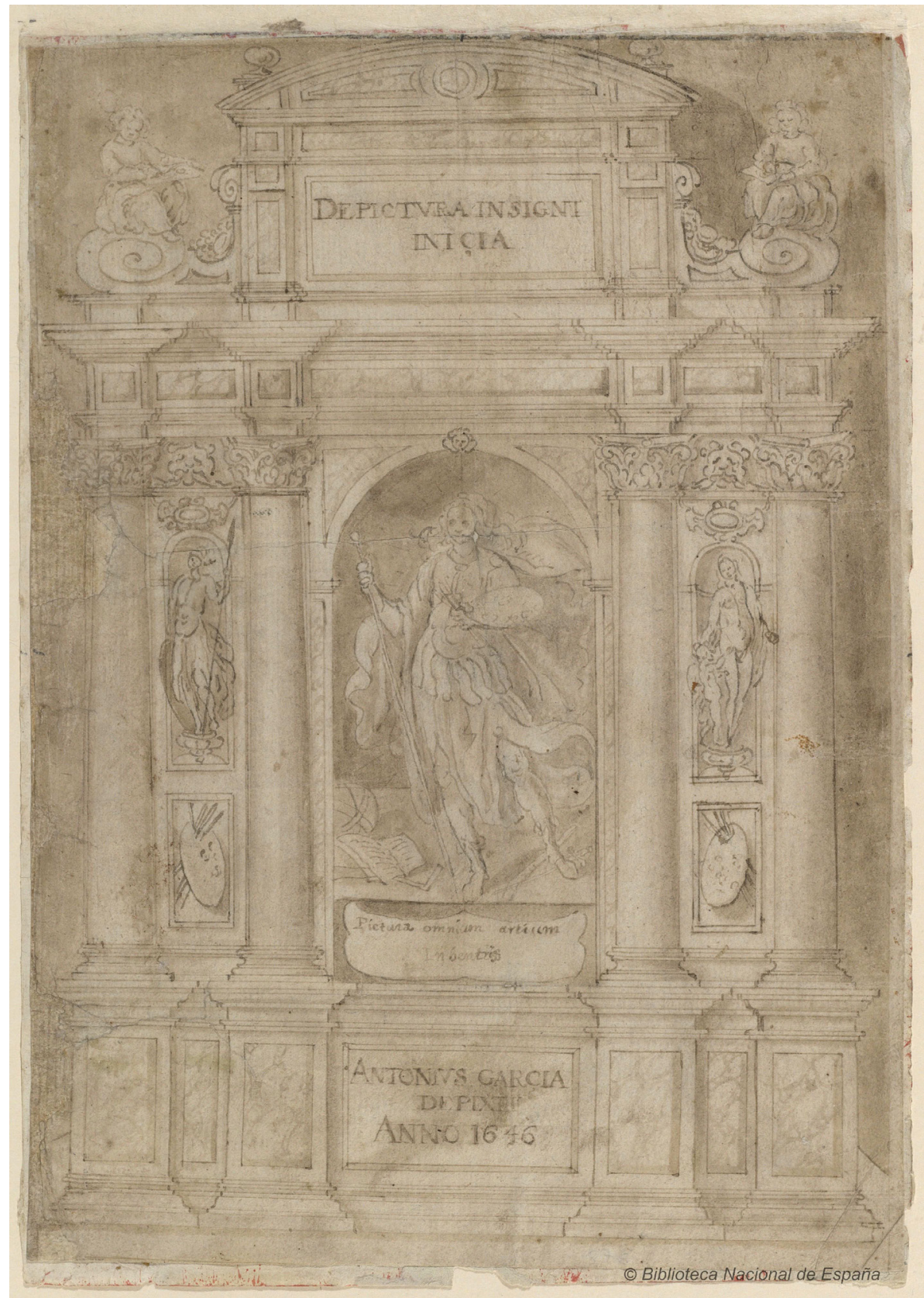

Figura 3. Antonio García Reinoso, Portada del Álbum de García Reinoso, 1646, Biblioteca Nacional de España, Madrid (Inv ${ }^{\circ}$ DIB/18/1/876/1)..

LABORATORIO DE ARTE 32 (2020), pp. 183-206, ISSN 1130-5762

e-ISSN 2253-8305 - DOI http://dx.doi.org/10.12795/LA.2020.i32.10 
Figura 4. Antonio García Reinoso,

Proyecto de retablo con custodia, Museo de Bellas Artes de Córdoba $\left(\mathrm{N}^{\circ} \mathrm{R}^{\circ} \mathrm{CE} 1036 \mathrm{D}\right)$.

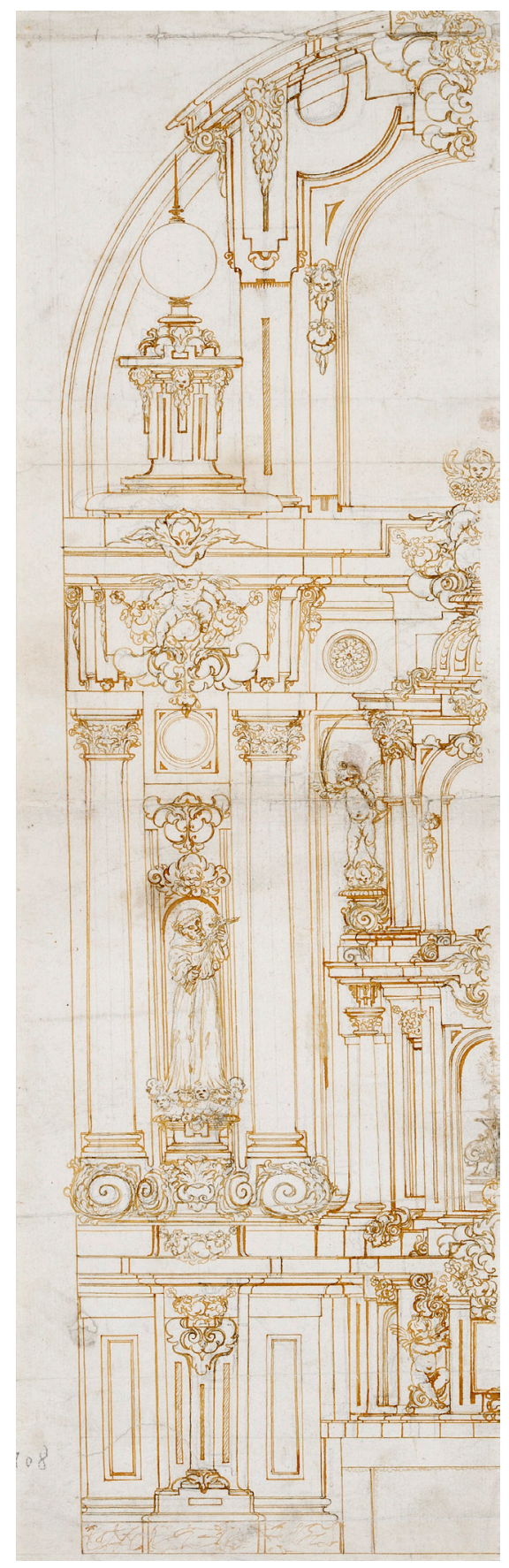

LABORATORIO DE ARTE 32 (2020), pp. 183-206, ISSN 1130-5762 e-ISSN 2253-8305 - DOI http://dx.doi.org/10.12795/LA.2020.i32.10 


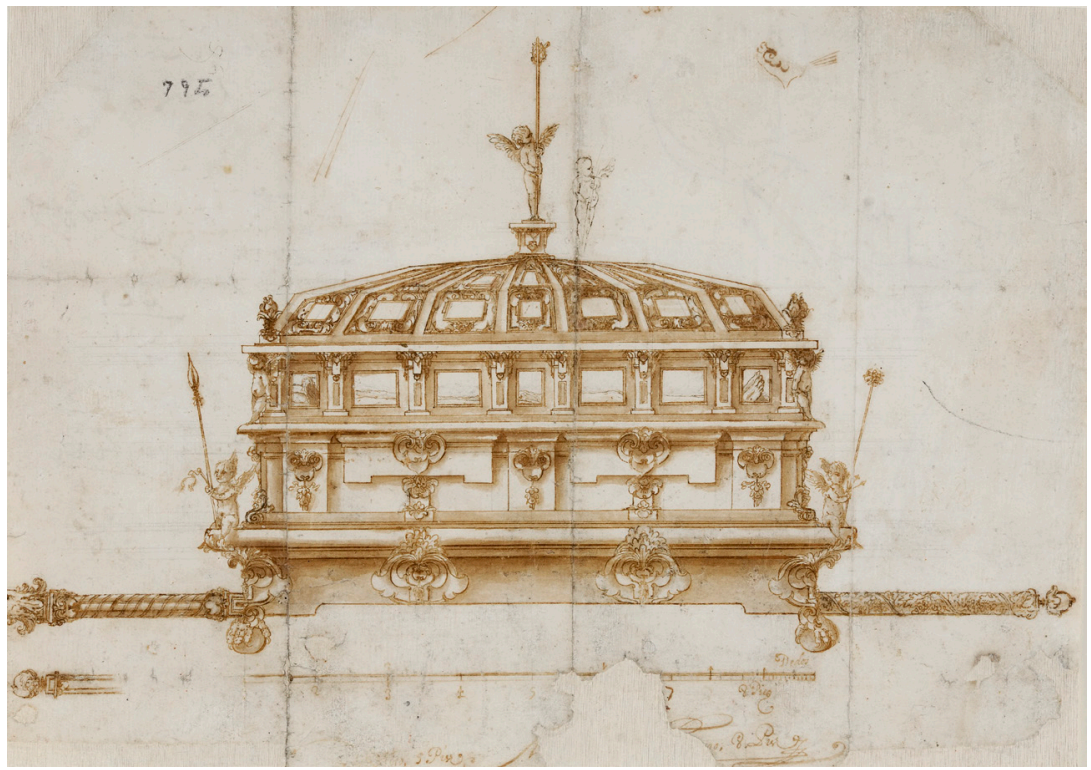

Figura 5. Antonio García Reinoso, Proyecto de urna para el Santo Entierro, Museo de Bellas Artes de Córdoba $\left(\mathrm{N}^{\circ} \mathrm{R}^{\circ} \mathrm{CE} 1055 \mathrm{D}\right)$.

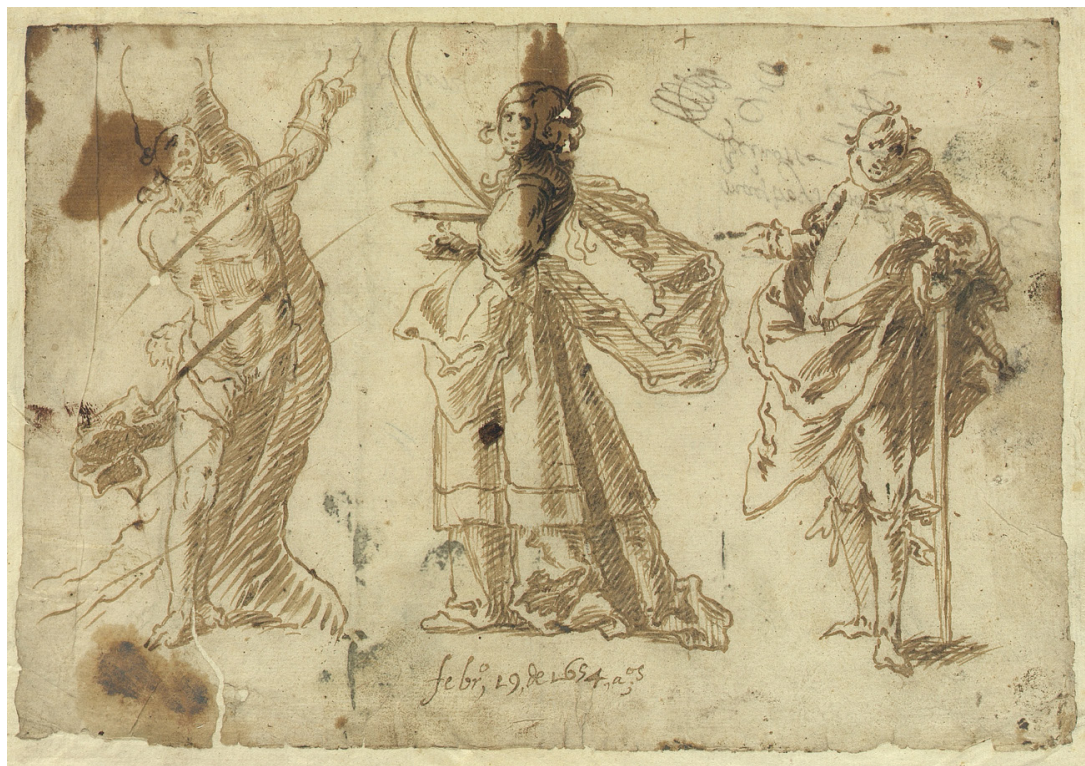

Figura 6. Antonio García Reinoso, San Sebastián y dos figuras teatrales (?), 1654, Real Academia Española de Madrid, colección Rodríguez-Moñino Brey (Inv ${ }^{\circ}$ DRM 746$)$. 


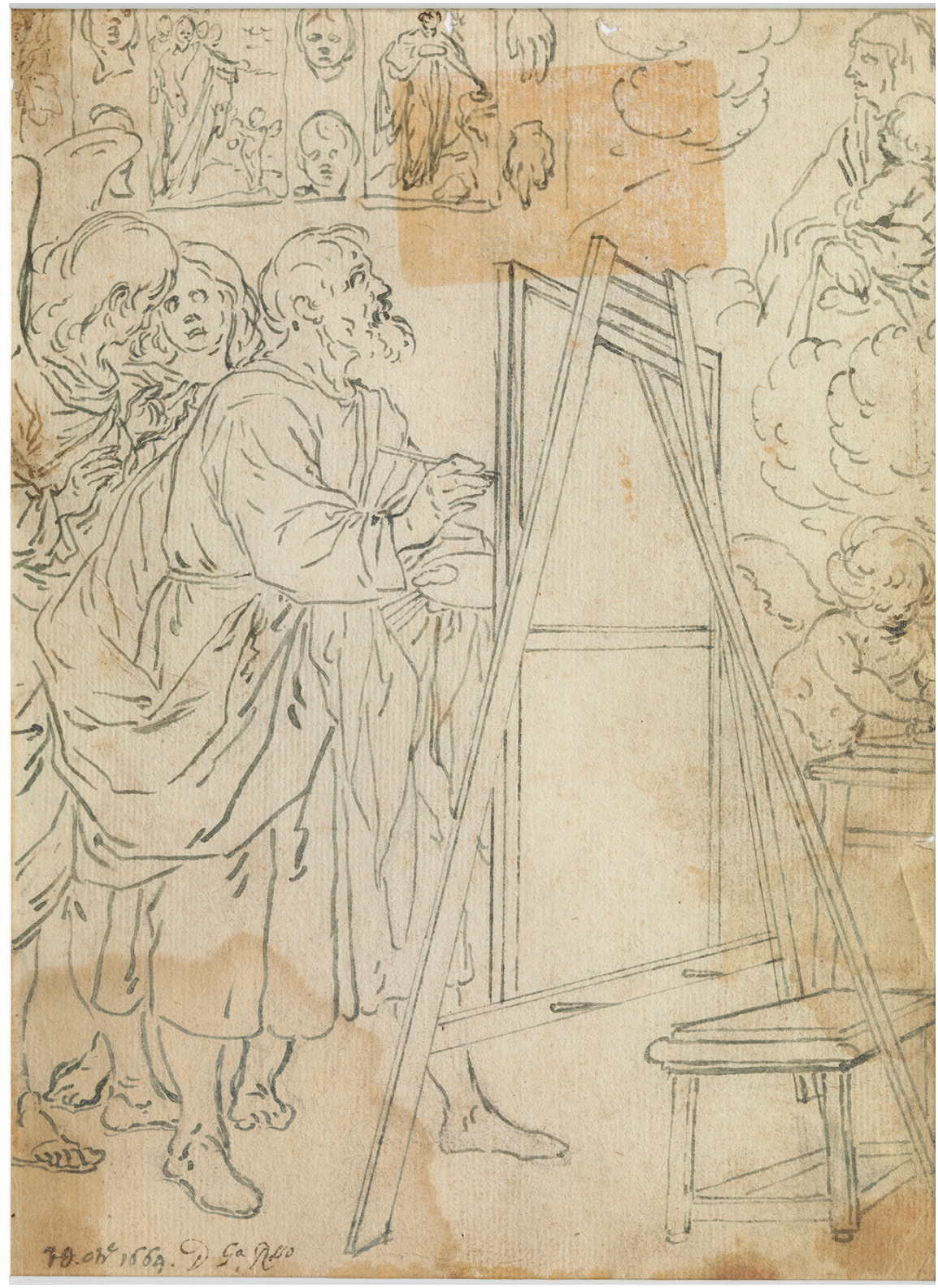

Figura 7. Antonio García Reinoso, San Lucas pintando a la Virgen, 1664, colección privada. 


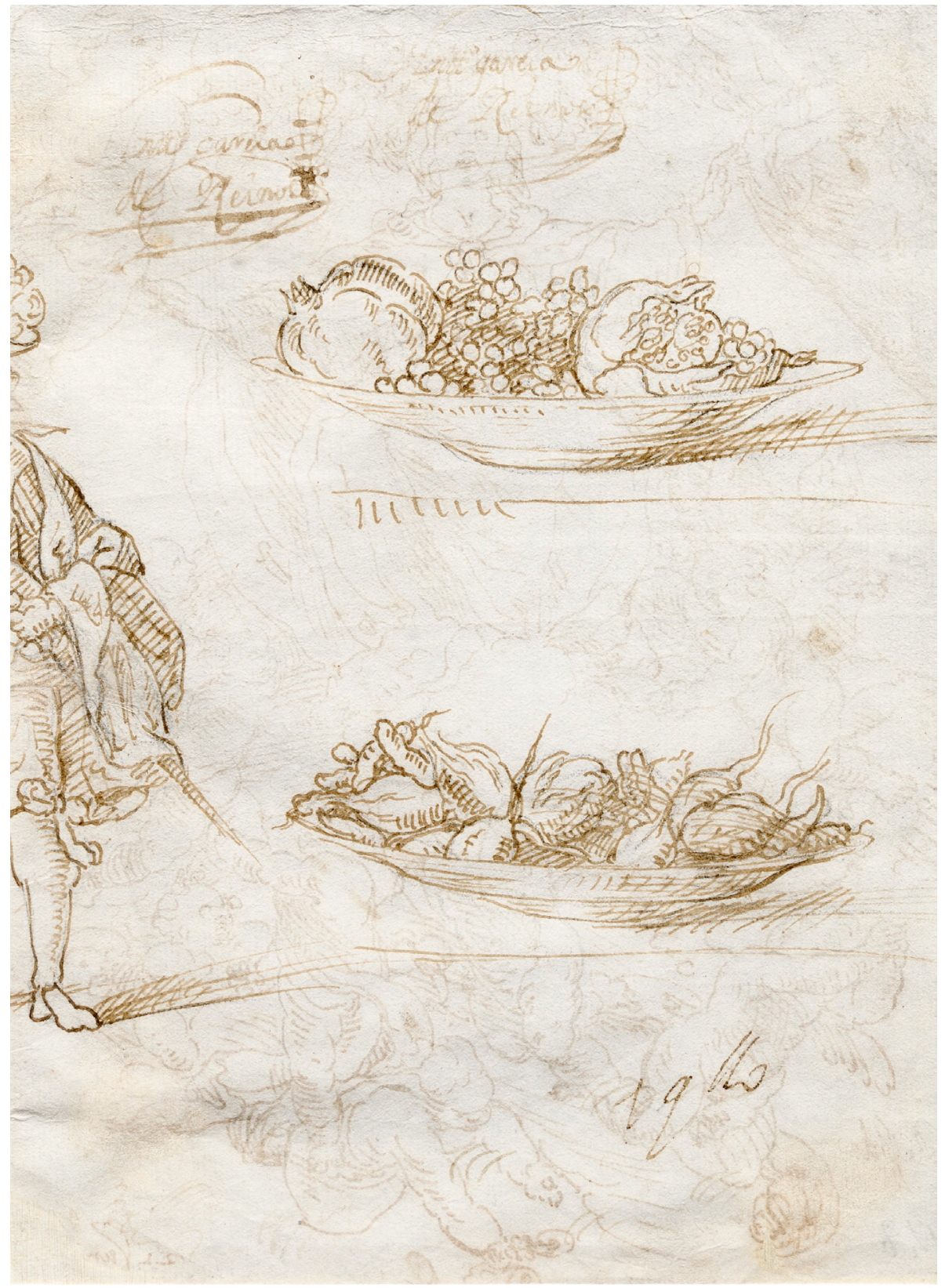

Figura 8. Antonio García Reinoso, Bandejas de frutas y de hortalizas y fragmento de un caballero, al dorso de la Asunción de la Virgen, 1648, Museo de Bellas Artes de Córdoba ( $\left.\mathrm{N}^{\circ} \mathrm{R}^{\circ} \mathrm{CE} 0994 \mathrm{D}\right)$. 